\title{
CAPTCHA: Impact on User Experience of Users with Learning Disabilities
}

\author{
Ruti Gafni and Idan Nagar \\ The Academic College of Tel-Aviv-Yaffo, Yaffo, Israel
}

\author{
rutigafn@mta.ac.il; Idan.nagar@gmail.com
}

\begin{abstract}
CAPTCHA is one of the most common solutions to check if the user trying to enter a Website is a real person or an automated piece of software. This challenge-response test, implemented in many Internet Websites, emphasizes the gaps between accessibility and security on the Internet, as it poses an obstacle for the learning-impaired in the reading and comprehension of what is presented in the test. Various types of CAPTCHA tests have been developed in order to address accessibility and security issues. The objective of this study is to investigate how the differences between various CAPTCHA tests affect user experience among populations with and without learning disabilities. A questionnaire accompanied by experiencing five different tests was administered to 212 users, 60 of them with learning disabilities. Response rates for each test and levels of success were collected automatically. Findings suggest that users with learning disabilities have more difficulties in solving the tests, especially those with distorted texts, have more negative attitudes towards the CAPTCHA tests, but the response time has no statistical difference from users without learning disabilities. These insights can help to develop and implement solutions suitable for many users and especially for population with learning disabilities.
\end{abstract}

Keywords: CAPTCHA, cyber security, user experience, learning disabilities, dyslexia

\section{Introduction}

Malicious programs try to access Websites for many reasons. One of the main issues of cyber security deals with the question whether the agent trying to reach a Website is a real person or a malicious automated program ("bot"). One of the most common solutions to decide whether the agent trying to access the Website is legal is called CAPTCHA (Completely Automated Public Turing test to tell Computers and Humans Apart). The first CAPTCHA test was invented by Luis von Ahn, Manuel Blum, Nicholas Hopper, and John Langford of Carnegie Mellon University in 2000 and is still used today (Singh \& Pal, 2014). The "T" in the name stands for "Turing Test to

(CC BY-NC 4.0) This article is licensed to you under a Creative Commons AttributionNonCommercial 4.0 International License. When you copy and redistribute this paper in full or in part, you need to provide proper attribution to it to ensure that others can later locate this work (and to ensure that others do not accuse you of plagiarism). You may (and we encourage you to) adapt, remix, transform, and build upon the material for any non-commercial purposes. This license does not permit you to use this material for commercial purposes.

\section{Tell", because CAPTCHA tests are like Turing} Tests. In the original Turing Test, a human judge was instructed to ask a series of questions to two players, without seeing them, one of which was a computer and the other a human. Both players pretended to be the human, and the judge had to distinguish between them. CAPTCHA tests are similar to the Turing Test in that they distinguish humans from computers, but they differ in that the judge is now a computer (Von Ahn, Blum, \& Langford,

\section{Editor: Janice Whatley}

An earlier, shorter version of this paper was presented at the Chais conference 2016, in Raanana, Israel, and included in Y. Eshet-Alkalai, I. Blau, A. Caspi, N. Geri, Y. Kalman, \& V. Silber-Varod (Eds.), Proceedings of the 11th Chais Conference for the Study of Innovation and Learning Technologies 2016: Learning in the Technological Era. Raanana: The Open University of Israel. 
2004). Using the CAPTCHA tests can prevent instances of spam in blogs, protect Website registrations, protect Email addresses from scrapers, prevent attacks, etc., while ensuring that those who enter the Website are only human people. The test performs a challenge-response authentication process, presenting a challenge to the user, and the right to access the Website is given if solved. If the user fails to solve the test then he/she is considered to be a machine, otherwise the user is considered as an authentic human being user, and the access is allowed. The user must use cognitive abilities, which are at the present time impossible for machines (Saini \& Bala, 2013).

Cyber threats became abundant, and the attempts to reach computers by unauthorized agents are growing. Therefore, CAPTCHA implementations can be found on more than 3.5 million sites globally, in all kinds of Websites, like sites for fill-in forms, write comments, buy tickets, etc., and human beings solve CAPTCHA tests more than 300 million times a day (Angre, Kapadia, \& Ugale, 2015). Moreover, companies and researchers are looking forward to replacing passwords with CAPTCHA tests, expanding even more the usage of CAPTCHA (Hande, \& Ali, 2015; Reddy, Krishna, \& Reddy, 2015).

The conflict between approachability and protection in the internet world is a complex issue, dealing with the necessity to allow a wide range of different users to access the desired Website, but preventing the access of malicious elements. CAPTCHA tests are an efficient approach to this goal, but are difficult for users with learning disabilities (LD), who have difficulties in reading, understanding, and performing the tests. CAPTCHA tests must be, on the one hand, very easy for the user in order to pass, and, on the other hand, very difficult for the bots to pass.

There are some definitions of Learning Disabilities, which were first defined by Hammill (1990). Since then, the definition was developed and re-defined. According to Katchergin (2015), researchers and professionals in the field of disabilities tend to base their definitions on those of the NJCLD (National Joint Committee on Learning Disabilities, 1994). The NJCLD definition claims that "Learning Disabilities" is a general term that refers to a heterogeneous group of disorders manifested by significant difficulties in the acquisition and use of listening, speaking, reading, writing, reasoning, or mathematical skills. These disorders are intrinsic to the individual, presumed to be due to central nervous system dysfunction. The number of people with learning disabilities in the population is not known exactly, but the numbers used by the professionals varied from $3 \%$ to $30 \%$, with the most frequent estimate being $10 \%$ (Katchergin, 2015). Sometimes this percentage can be higher in practice, and it is even estimated that one-third of internet users suffer from certain symptoms of learning disabilities (McCarthy \& Swierenga, 2010). According to the study of Foley (2012), the most common learning disability is dyslexia. Dyslexia (from Greek, dys=difficulty + lexis=words), also known as reading disorder, is a learning disability characterized by trouble reading despite one's normal intelligence. A dyslexic person has difficulty in associating the graphic symbols and letters with their corresponding sounds and cannot organize them mentally in a correct sequence (Madeira, Silva, Marcelino, \& Ferreira, 2015). Different people are affected to varying degrees. Problems may include sounding out words, spelling words, reading quickly, writing words, pronouncing words when reading aloud, and understanding what one reads. Often these difficulties are first noticed at school. The cause of dyslexia is believed to involve both genetic and environmental factors. It occurs most often in people with attention deficit hyperactivity disorder (ADHD) and is associated with problems with mathematics. The underlying mechanism involves problems with the brain's processing of language. Dyslexia is diagnosed by a series of tests of a person's memory, spelling, ability to see, and reading skills. It is separate from reading difficulties due to poor teaching, or hearing or vision problems (Katchergin, 2015).

People with learning disabilities may find it difficult and disturbing to succeed in performing the CAPTCHA tests, because they consist in combining cognitive and physical effort. They must 
read distorted texts, understand them, perform calculations, and even move small pictures with accuracy.

Many studies have been conducted on CAPTCHA, focusing on the security analysis (Azad, 2013), on the differences between types of tests (Foley, 2012; Singh \& Pal, 2014), and examining the combination between security and user friendliness (Gossweiler, Kamvar, \& Baluja, 2009). Only few focused on the user experience (Fidas, Voyiatzis, \& Avour, 2011; Tangmanee \& Sujarit-apirak, 2013). This research deals with the influence of CAPTCHA tests among users having learning disabilities, examining user experience, actual performance, and success.

\section{Theoretical Background}

\section{User Disabilities, Accessibility, and User Experience}

Bevan's (2009) study describes the user experience as including emotions, beliefs, preferences, conceptions, psychological and physical reactions, behaviors, and achievements occurring before, during, and after usage. According to Onwudebelu, Sanjo, Obi, and Alaba (2010), the use of CAPTCHA tests is a nuisance. Some users feel threatened by these tests, irritated, and frustrated, as they are unable to understand the need for it. Others reported that the text displayed is unclear, and they struggle to solve it. Most reported the tests slow them down and interfere with their activity on Websites.

Web accessibility has become an important issue since the dramatic rise in the use of the Internet. Web accessibility deals with overcoming barriers, which users with disabilities face when trying to access information on Websites. In some countries (U.S.A., Israel, etc.) laws relating to Internet accessibility were legislated, in order to improve the usability of the Internet for disabled users. However, a large number of Websites are still not adapted. For example, nearly a third of the official government Web sites of the 50 states and the District of Columbia tested did not meet the most fundamental requirements for Web accessibility (White, Goette, \& Young, 2005). There are many recommendations for development of appropriate and friendly Websites that need to be accessible towards those users, and in this way improve the experience for internet users (McCarthy \& Swierenga, 2010; Pascual, Ribera, \& Granollers, 2015), including guidelines (W3C, 2008) and clear principles (Matej, 2013). These recommendations help and encourage designers and web developers to make Websites accessible to all users, including users with disabilities and impairments (Foley, 2012). The Internet may greatly facilitate the provision of accessible information to people with learning disabilities. However, problems of navigation and, therefore, retrieval represent a barrier for this cohort. A study conducted by Williams and Hennig (2015) examined how the Web-page design affects the access to content for people with learning disabilities. For example, they examined whether the orientation of the page, vertical or horizontal, and the positions of the words in the page facilitate faster access. They found that the propensity to imbibe information "serially" (word-for-word) rather than to skim or look "globally" has important Website design implications. According to Sagirani, Nugroho, Santosa, and Kumara (2015) there are some recommendations and basic concepts in creating a design that can foster user experience. Planning the product should focus on the content, presentation, functionality, and interaction. Specifically, good interaction between users with limitations and the application can provide improvements for children with special educational needs, especially on their cognition, emotion, motivation, attention, perception, and behavior. Aside from accessibility difficulties, frustration, and poor user experience (Ghazarian, 2014), user abandonment and decline in the website's conversion rates (the percentage of visitors who take a desired action) are additional consequences of CAPTCHA tests suffering from user-unfriendliness (Mujumdar \& Polisetti, 2011). 
The activity of CAPTCHA tests needs to be trivial enough to be performed successfully by human persons, but they often present some difficulties (Singh \& Pal, 2014). Each of the different types has some drawbacks.

\section{Types of CAPTCHA Tests}

During the last years, several types of CAPTCHA tests have been defined and developed. Each type has its pros and cons. Here are the descriptions of the most common types of CAPTCHA tests:

Text-based CAPTCHA test - is the most used kind of test (Figure 1), called "reCAPTCHA", consisting of a sequence of numbers and letters, twisted and shown in a distorted manner. This mechanism was originally aimed to help digitize printed text that was hard to read for OCR (Optical Character Recognition) and was acquired by Google in 2009, in order to digitize antique manuscripts ("reCAPTCHA", n.d.). The user needs to identify and decipher what is shown and then type the exact sequence into a text box. If the user cannot decipher the text, it is possible to retry with a different text. There is also an option to hear the letters, which was developed for vision-impaired people. The user hears a sequence of letters and/or numbers and must type the sequence in the text-box, but this is often performed with a noisy background, which does not help too much.

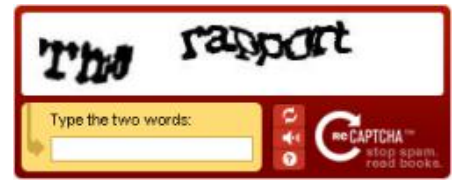

Figure 1. Text-based CAPTCHA

In 2013, reCAPTCHA began implementing behavioral analysis of the browser's interactions with CAPTCHA. This analysis (Figure 2) occurs before displaying the CAPTCHA and presents a more difficult test in cases there are reasons to think the user is a bot. From 2014 this mechanism, called "No CAPTCHA reCAPTCHA", started to be used in most of Google services ("reCAPTCHA", n.d.).

\section{I'm not a robot}

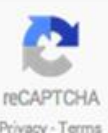

Figure 2. No CAPTCHA reCAPTCHA

Arithmetic operation based CAPTCHA test - contains a very basic arithmetic operation, for example " $1+3=$ " (Figure 3 ), which can be performed by almost every human being. The user needs to enter the result of the operation into a text box.

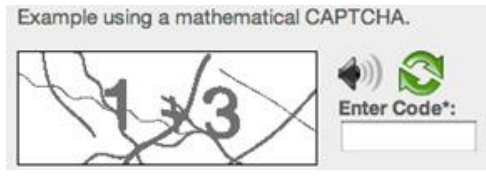

Figure 3. Arithmetic operation CAPTCHA 
Picture based CAPTCHA test - in this kind of test, a number of pictures are shown to the user with a simple question. In the example shown in Figure 4, there are eight different pictures, of which four show "piggy banks". The user is asked to click on all of the piggy bank images. The user must identify the pictures and select those which represent the correct answer, and there is no need to write any text. There are some variations of the picture-based CAPTCHA, for example, sliding distorted pictures to arrange them (Figure 5).

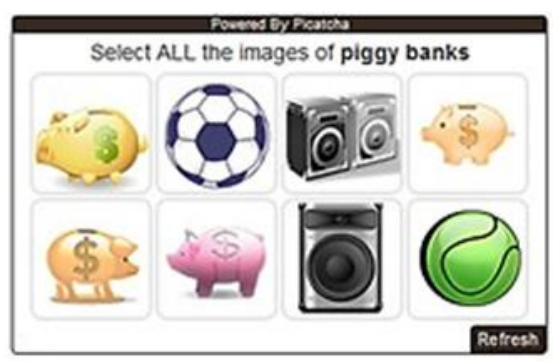

Figure 4. Picture based CAPTCHA

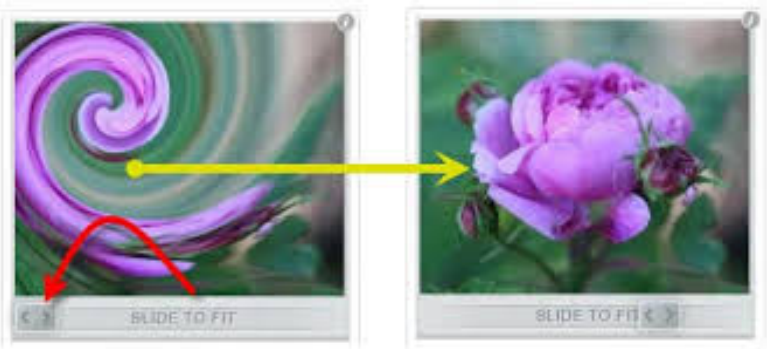

Figure 5. Sliding picture based CAPTCHA (from http://www.geekandblogger.com)

Game based CAPTCHA test - includes puzzles or interactive games (Mohamed et al., 2013). User experience and gamification are some of the "buzzwords" in the last years (Robson, Plangger, Kietzmann, McCarthy, \& Pitt, 2015). In order to encourage the users to perform tedious but substantial tasks, the activity is wrapped with a joyful function. In Figure 6, an example of a game can be seen, where the user needs to drag the pictures of items that are food to the baby's mouth.

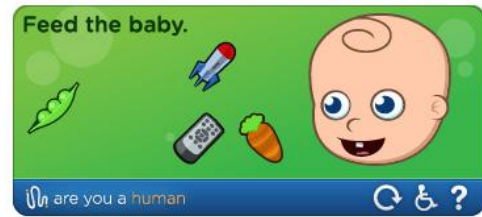

Figure 6. Game based CAPTCHA

\section{CAPTCHA Tests and Users with Disabilities}

In the text-based CAPTCHA test, the user experiences difficulties deciphering and identifying the characters due to the blurring of the characters displayed and their distortion. According to Foley's study (2012), the text-based CAPTCHA test has many accessibility problems. For example, visually impaired or almost blind users find the distorted text difficult to decipher, and sometimes even completely impossible to see. This means that they are not able to pass this test. For people with dyslexia, the ability to read and understand text can be affected by the way in which text has been written and produced, therefore, users with learning disabilities might also find it difficult to 
identify correctly the characters displayed in this test, which in turn will cause them to fail the test as well. Hsu and Lee (2011) found that older users show greater difficulty in passing a text-based CAPTCHA in comparison to younger users, and that even non-disabled users may encounter difficulties recognizing and understanding the distorted characters. Bursztein, Bethard, Fabry, Mitchell, and Jurafski (2010) found that the response times of older users were longer, while they made fewer mistakes. Furthermore, a "bot" can have the ability to recognize the character sequence using Optical Character Recognition (OCR) software. In order to prevent access from bots, Azad (2013) suggested to raise the security of text -based CAPTCHA by adding "noise", increasing the level of distortion of the characters and aligning the characters more closely; yet, this would make it more difficult for users to identify the characters, causing more mistakes.

Mostly, CAPTCHA tests require the deciphering of a sequence of deformed characters in Latin letters. This means that the text-based CAPTCHA test, the most common type being used today, requires that users be able to know and read Latin letters. For Thai internet users, English is a less familiar language, so for them, tests in Thai could prove to be a more suitable option. Tangmanee and Sujarit-apirak (2013) claimed that Thai users are well aware of the existence of CAPTCHA, but prefer an application using Thai language, which they are more familiar with. The study of Fidas et al. (2011), explains that Greek users have also experienced difficulties using CAPTCHA. Users whose mother tongue is not written in Latin letters frequently find CAPTCHA more challenging. Some CAPTCHA tests were defined in other languages, for example, in Arabic and Persian (Shirali-Shahreza, \& Shirali-Shahreza, 2006).

In the audio-based type, the sound clips played are based on the English language, and therefore the user must understand English; in addition, there is a problematic side to recognizing similarsounding letters. Moreover, the text is played together with "noise", in order to pose a challenge to "bots", and that makes this solution less than ideal as it poses a problem for users who have a hearing impairment or suffer from hearing loss, which, according to the World Health Organization, consists of more than 5\% of the population (WHO, 2015). According to Onwudebelu et al., (2010), while audio-based CAPTCHA tests are more commonly used for the visually impaired, they do not provide full accessibility and are even characterized by a lower degree of security.

Picture-based CAPTCHA tests require recognition and selection of images with a similar or an exceptional meaning or out of a sequence of images and may cause confusion, as the images can sometimes be interpreted as having different meanings (Ahn, Kim, \& Kim, 2013). Some studies propose variations of the tests, in order to simplify them, but these propositions are not widely used yet (Ahn et al., 2013; Gossweiler et al., 2009). Picture-based CAPTCHA tests do not pose many of the problems faced by users with learning disabilities; however, in these tests, visually impaired users still come across challenges similar to those of the text-based tests and struggle to pass the tests (Foley, 2012).

Preliminary results of the study of Madeira et al., (2015), dealing with mobile applications' usability for dyslexic users, show that a gamified set of activities allow dyslexics to improve multisensory perception, constituting an added value facilitator of adaptiveness and learning. Thus, game-based CAPTCHA tests may be the best choice for these users.

CAPTCHA tests must be easy for the user to pass successfully and be sufficiently difficult to prevent the "bots" from passing them. However, most studies focus primarily on how to make the tests more difficult for bots, in response to the growing number of security threats.

The CAPTCHA test supposedly provides an efficient method to distinguish between real users and "bots". However, the extensive use of CAPTCHA actually impairs the experience of users with disabilities, and using this method is not the ideal solution in the long-term (Onwudebelu et al., 2010). It emphasizes the gap between accessibility and security on the Internet, as it poses an obstacle and a significant challenge for the visually impaired or learning-impaired in the reading 
and comprehension of what is presented in the test, seeing that it provides significant challenges to users who have impaired vision or have learning disabilities.

\section{Research Questions and Hypotheses}

The objective of this study is to investigate the differences between various CAPTCHA tests and examine how they affect user experience among populations with and without learning disabilities. For this purpose three questions were examined in the study.

People with learning disabilities find it difficult to read regular text, so reading and deciphering distorted letters (Foley, 2012; Hammill, 1990; Katchergin, 2015), such as in the Text-based or Arithmetic based CAPTCHA test, will prolong their efforts in reading, and therefore the response time may be longer. However, gamification of the test may be an easier task for users with learning disabilities (Madeira et al., 2015), taking less time to perform it. Thus, the first research question and its hypothesis are:

RQ1: Are there any differences in the response time of users with or without learning disabilities?

H1: The performance time of users with learning disabilities will be longer in text and arithmetic based tests

The difficulties that users with learning disabilities need to cope with may cause frustration and decrease motivation (Katchergin, 2015; McCarthy \& Swierenga, 2010), therefore it may result in failures. However, when using CAPTCHA tests that are not based on letters and numbers, their performance may be higher (Madeira et al., 2015). Thus, the next research question has two complementary hypotheses:

RQ2: Are there any differences in the success rate of users with or without learning disabilities?

H2.1: The success rate of users without learning disabilities will be greater.

H2.2: Users with learning disabilities will succeed better in tests, which do not include letters.

According to prior studies, users found it annoying to perform the CAPTCHA tests (Onwudebelu et al., 2010). Those users with learning disabilities will find these tests more frustrating. However, their attitude may be better with the Picture and Game based tests, because in these tests the text parts are smaller and not distorted. Therefore, the third research question has two hypotheses:

RQ3: Are there any differences in the attitude and user experience of users with or without learning disabilities?

H3.1: Attitude and user experience of users with learning disabilities will be more negative.

H3.2: Users with learning disabilities will report better experience in tests, which do not include letters.

\section{Methodology}

The data for this study was collected using an experiment, which was embedded into a questionnaire.

The first part of the questionnaire was composed of 11 demographic and general information questions. The next five parts, each dealt with one of the following CAPTCHA tests: 


\section{Text-based CAPTCHA}

2. Arithmetic operation-based CAPTCHA

3. Picture-based CAPTCHA, using the version with the slider option, developed by Minteye Company (www.minteye.com)

4. Game-based CAPTCHA, developed by Are-you-a-human Company (www.areyouahuman.com)

5. "No CAPTCHA”, developed by Google Company (www.google.com/recaptcha)

The participants were asked to actually perform and solve each test, and immediately after that to answer 10 questions about their experience using each one of the tests. The same questions were asked about each of the tests. The responses were based on a five-level Likert-type scale (1 'Strongly disagree', to 5 - 'Strongly agree'). Altogether, each participant answered 61 questions and performed 5 different tests.

While the participants tried to solve the tests, a specifically developed hidden script automatically accumulated the data about the success or failure of the respondent in using each test and the time it took to complete it.

The questionnaire and experiment, which were built as a single unit using a plug-in based on WordPress, which is a free and open-source web content management system, were delivered primarily via the Internet, both through social media like Facebook (Baltar \& Brunet, 2012), and through Websites and forums related to learning disabilities.

The combination of both research methods was based on the study conducted by Abrich, Berbenetz, and Thrope (2011), which defined the quality of user experience on whether the user was correct or not when taking a test, as well as on the level of test difficulty the user reported.

The answers were collected during one week (December 2014), and then gathered and analyzed using IBM ${ }^{\circledR}$ SPSS ${ }^{\circledR}$ Statistics.

\section{Results}

In the first part of the questionnaire, the respondents had to give demographic data and information about their previous familiarity with the different CAPTCHA tests.

There were 212 respondents, 60 reporting having learning disabilities or thinking they have but not diagnosed yet (28\%) and 152 without learning disabilities $(72 \%)$.

The frequency of Internet usage was similar and high in the two groups (4.7 in LD and 4.88 in non-LD).

Table 1 supplies demographics descriptive statistics of the participants in the questionnaire and experiment. 
Table 1: Demographics of the survey participants

\begin{tabular}{|l|l|l|}
\hline $\mathbf{N}$ & 212 & \\
\hline Gender & 99 men & $(47 \%)$ \\
& 113 women & $(53 \%)$ \\
\hline \multirow{2}{*}{ Age } & 18 and under -6 participants & $(3 \%)$ \\
& $19-30-141$ participants & $(66 \%)$ \\
& $31-45-46$ participants & $(22 \%)$ \\
& $46-59-14$ participants & $(7 \%)$ \\
& 60 and above -5 participants & $(2 \%)$ \\
\hline \multirow{2}{*}{ Education } & $21-$ high school & $(10 \%)$ \\
& $118-$ Undergraduate students & $(56 \%)$ \\
& $46-$ Bachelor degree & $(22 \%)$ \\
& $27-$ Master and higher degrees & $(13 \%)$ \\
\hline
\end{tabular}

Table 2 summarizes the familiarity of the users (with and without learning difficulties) with each CAPTCHA test. The mean value and standard deviation are shown. As seen, the text-based CAPTCHA is the most familiar to the users, and the arithmetic operation based one is also known. Most of the users are not so familiar with the other three types.

Table 2. Familiarity with the CAPTCHA tests ( 1 - 'Never', 5 - 'Very often')

\begin{tabular}{|c|l|c|c|c|}
\hline CAPTCHA type & $\begin{array}{c}\text { LD users } \\
(\mathbf{n = 6 0})\end{array}$ & $\begin{array}{c}\text { Non-LD users } \\
(\mathbf{n = 1 5 2})\end{array}$ & $\begin{array}{c}\text { Total } \\
(\mathbf{n = 2 1 2})\end{array}$ \\
\hline \multirow{2}{*}{1.} & Text based & 3.88 & 3.92 & 3.91 \\
& & $(1.01)$ & $(0.94)$ & $(0.96)$ \\
\hline 2. & Arithmetic operation based & 2.48 & 2.19 & 2.28 \\
\hline & & $1.25)$ & $(1.26)$ & $(1.26)$ \\
\hline 3. & Picture based & $(0.18)$ & 1.2 & 1.15 \\
& & 1.13 & $(0.63)$ & $(0.55)$ \\
\hline & Game based & $(0.5)$ & 1.1 & 1.11 \\
5. & “NO CAPTCHA" based & 1.33 & $(0.43)$ & $(0.45)$ \\
\hline
\end{tabular}

The general position of the respondents towards CAPTCHA, according to prior experiences and before the experiment was conducted, was collected by a set of statements, for which the participant had to rate his agreement on a Likert based scale. Table 3 summarizes the means for each statement, for the users with learning disabilities, for those without learning disabilities, and for the whole sample. As can be seen, the users understand the purpose of the tests (4.19), but this understanding does not cause them to feel protected (2.83). Moreover, most of the users do not like to use the CAPTCHA tests.

It is important to emphasize, that according to Table 2, most of the users are familiar only with the text-based and arithmetic-based tests. Moreover, there is a prominent difference between the two kinds of users for two types of CAPTCHA: users with learning disabilities are more familiar with arithmetic-based test, while they are less familiar with the latest type, the "NO CAPTCHA" test. 
Table 3: General position towards CAPTCHA tests

\begin{tabular}{|l|c|c|c|}
\hline \multicolumn{1}{|c|}{ Statement } & LD users & Non-LD users & Total \\
\hline $\begin{array}{l}\text { "I understand the meaning and the purpose of CAP- } \\
\text { TCHA tests" }\end{array}$ & 3.97 & 4.28 & 4.19 \\
\hline "I feel frustrated / I hate it" & 3.32 & 2.94 & 3.05 \\
\hline "I feel that I spend too much time on it" & 3.98 & 3.41 & 3.57 \\
\hline "I feel protected / safe" & 2.95 & 2.79 & 2.83 \\
\hline $\begin{array}{l}\text { "I prefer something more comfortable instead of this } \\
\text { test / I prefer it would not exist" }\end{array}$ & 3.83 & 3.64 & 3.70 \\
\hline
\end{tabular}

Thereafter, the participants were asked to solve the first test and immediately answer some questions about their experience. This was done with the other four tests as well.

After performing each of the CAPTCHA tests, the participants were asked to rate their experience with the test, in terms of the extent to which they agree with the following statements:

\section{The experience after the CAPTCHA test:}

"How would you describe your feeling after taking this CAPTCHA test?"

Item 1.1: "Frustrating - the test was difficult and unclear"

Item 1.2: "A waste of time - It took too much time to do it"

Item 1.3: "Comfortable/Enjoyable - It was a nice test"

\section{The position towards this CAPTCHA test:}

"If you have to take this CAPTCHA test again, what will your position be towards this test?"

Item 2.1: "I would rather do it again-since it's easy and clear"

Item 2.2: "I would rather do it again-since it takes only a short time to do it"

Item 2.3: "I would rather do it again - since it's nice and comfortable"

\section{The position towards the Website:}

"If you have to take this CAPTCHA test again, what will your position be towards the Website that displays this test?"

Item 3.1: "My position will be positive"

Item 3.2: "I will not cooperate with this site - I will leave this site immediately"

Item 3.3: "I will not cooperate with this site - I will not perform actions such as registration, buying, etc."

The outputs of the respondents' experience are summarized in Table 4, which gives the items' means and standard deviation, the constructs built according to the statements, and their reliability, measured by Cronbach's alpha. Principal component factor analysis with Varimax rotation was used to examine construct validity. Three items were intended to comprise one factor, 'Unwillingness to use the Website', but one item (3.1) was statistically excluded. The 1.3 statement was intended to be included in the 'Frustrating' construct (negative), but it was found that it loaded a different factor. Finally, four constructs were defined: 'Frustrating', 'Enjoyable', 'Readiness for future use', and 'Unwillingness to use the Website'. 
Table 4. User experience constructs definition

\begin{tabular}{|c|c|c|c|c|}
\hline Item & Mean (SD) & Cronbach's alpha & Construct & Mean (SD) \\
\hline 1.1 & $3.94(1.28)$ & \multirow{2}{*}{.802} & \multirow{2}{*}{ Frustrating } & \multirow{2}{*}{$3.86(1.23)$} \\
\hline 1.2 & $3.78(1.40)$ & & & \\
\hline 1.3 & $2.94(1.49)$ & Separated & Enjoyable & $2.94(1.49)$ \\
\hline 2.1 & $3.07(1.48)$ & \multirow{3}{*}{.954} & \multirow{3}{*}{ Readiness for future use } & \multirow{3}{*}{$3.05(1.43)$} \\
\hline 2.2 & $3.09(1.48)$ & & & \\
\hline 2.3 & $3.00(1.52)$ & & & \\
\hline 3.1 & $2.89(1.34)$ & Deleted & & \\
\hline 3.2 & $4.29(1.07)$ & \multirow{2}{*}{.904} & \multirow{2}{*}{$\begin{array}{l}\text { Unwillingness to use the } \\
\text { Website }\end{array}$} & \multirow{2}{*}{$4.28(1.03)$} \\
\hline 3.3 & $4.26(1.09)$ & & & \\
\hline
\end{tabular}

The results (Table 5) indicate that there is a significant difference between users with learning disabilities and users without learning disabilities among the participants in two user experience constructs: 'Frustrating' and 'Unwillingness to use the Website'.

Table 5. Statistical results of User experience

\begin{tabular}{|c|c|c|c|c|c|c|c|}
\hline User Experience construct & LD User & $\mathbf{N}$ & Mean & SD & $\bar{T}$ & $\overline{\text { df }}$ & Sig. (2-tailed) \\
\hline \multirow[b]{2}{*}{ Frustrating } & No LD & 760 & 3.96 & 1.19 & \multirow[b]{2}{*}{3.961} & \multirow[b]{2}{*}{508.79} & \multirow[b]{2}{*}{.000} \\
\hline & LD & 300 & 3.62 & 1.29 & & & \\
\hline \multirow[b]{2}{*}{ Enjoyable } & No LD & 760 & 2.95 & 1.49 & \multirow[b]{2}{*}{.412} & \multirow[b]{2}{*}{1058} & \multirow[b]{2}{*}{.680} \\
\hline & LD & 300 & 2.91 & 1.50 & & & \\
\hline \multirow[b]{2}{*}{ Readiness for future use } & No LD & 760 & 3.07 & 1.43 & \multirow[b]{2}{*}{.627} & \multirow[b]{2}{*}{1058} & \multirow[b]{2}{*}{.531} \\
\hline & LD & 300 & 3.01 & 1.43 & & & \\
\hline \multirow{2}{*}{$\begin{array}{l}\text { Unwillingness to use the } \\
\text { Website }\end{array}$} & No LD & 760 & 4.34 & 0.96 & \multirow[b]{2}{*}{3.123} & \multirow[b]{2}{*}{463.18} & \multirow[b]{2}{*}{.002} \\
\hline & LD & 300 & 4.10 & 1.18 & & & \\
\hline
\end{tabular}

Table 6 summarizes the findings of the user experience of each of the CAPTCHA tests, according to the constructs defined. The gamed-based CAPTCHA was found to be the most enjoyable for users with learning disabilities, while the text-based was the least enjoyable and most frustrating.

Statistical differences between the group of users with learning disabilities and the group of users without were found in the 'Frustrating' construct in the text-based $(\mathrm{t}=-2.36, \mathrm{df}=210, \mathrm{sig}=$ $0.019)$ and arithmetic-operation-based $(\mathrm{t}=-3.294, \mathrm{df}=210, \mathrm{sig}=0.001)$ tests. 
Table 6. Comparison of means and sd - user experience for CAPTCHA types

\begin{tabular}{|c|c|c|c|c|c|}
\hline \multirow[b]{2}{*}{ САРТСНА type } & \multirow[b]{2}{*}{ LD User } & \multicolumn{4}{|c|}{ Post-test experience } \\
\hline & & Frustrating & Enjoyable & $\begin{array}{l}\text { Readiness for } \\
\text { future use }\end{array}$ & $\begin{array}{l}\text { Unwillingness to } \\
\text { use the Website }\end{array}$ \\
\hline \multirow[b]{2}{*}{ 1. Text based } & No LD & $3.56(1.10)$ & $2.05(1.17)$ & $2.42(1.12)$ & $4.30(0.87)$ \\
\hline & LD & $3.15(1.17)$ & $1.85(1.15)$ & $2.09(1.04)$ & $4.98(1.03)$ \\
\hline \multirow{2}{*}{$\begin{array}{l}\text { 2. Arithmetic operation } \\
\text { based }\end{array}$} & No LD & $4.52(1.03)$ & $3.01(1.47)$ & $3.30(1.42)$ & $4.45(0.85)$ \\
\hline & LD & $4.69(1.20)$ & $2.72(1.28)$ & $3.07(1.27)$ & $4.11(1.26)$ \\
\hline \multirow[b]{2}{*}{ 3. Picture based } & No LD & $3.94(1.15)$ & $3.34(1.42)$ & $3.31(1.44)$ & $4.37(0.95)$ \\
\hline & $\overline{L D}$ & $3.68(1.36)$ & $3.22(1.52)$ & $3.26(1.51)$ & $4.17(1.19)$ \\
\hline \multirow[b]{2}{*}{ 4. Game based } & No LD & $3.86(1.21)$ & $3.24(1.38)$ & $3.07(1.37)$ & $4.30(0.97)$ \\
\hline & LD & $3.68(1.23)$ & $3.55(1.47)$ & $3.19(1.39)$ & $4.29(1.13)$ \\
\hline \multirow{2}{*}{$\begin{array}{l}\text { 5. "NO CAPTCHA" } \\
\text { based }\end{array}$} & No LD & $4.20(1.31)$ & $3.11(1.63)$ & $3.24(1.56)$ & $4.28(1.13)$ \\
\hline & LD & $3.88(1.42)$ & $3.20(1.49)$ & $3.44(1.53)$ & $3.98(1.27)$ \\
\hline
\end{tabular}

As mention in the methodology section, each time the participant performed a test, two inputs were collected automatically: the response time to complete the test, and the output, to check if the test was performed successfully or if the answer was wrong.

As for response time, surprisingly, there were no significant differences between users with learning disabilities and those participants without learning disabilities for any of the CAPTCHA tests (Table 7).

Table 7. Comparison of the CAPTCHA types - Response Time

\begin{tabular}{|c|c|c|c|c|c|c|}
\hline \multirow[b]{3}{*}{ CAPТСНА type } & \multicolumn{4}{|c|}{ Response Time (in seconds) } & \multirow[b]{3}{*}{ t-test } & \multirow[b]{3}{*}{$\begin{array}{c}\text { Sig } \\
\text { (2-tailed) }\end{array}$} \\
\hline & \multicolumn{2}{|c|}{ Mean (SD) } & \multicolumn{2}{|c|}{ Median } & & \\
\hline & $\begin{array}{c}\text { LD } \\
\text { users } \\
(n=60)\end{array}$ & $\begin{array}{c}\text { Non-LD } \\
\text { users } \\
(n=152)\end{array}$ & $\begin{array}{c}\text { LD } \\
\text { users } \\
(n=60)\end{array}$ & $\begin{array}{c}\text { Non- } \\
\text { LD } \\
\text { users } \\
(\mathrm{n}=15 \\
2)\end{array}$ & & \\
\hline 1. Text based & $\begin{array}{c}22.25 \\
(12.73) \\
\end{array}$ & $\begin{array}{c}19.36 \\
(13.69) \\
\end{array}$ & 18 & 16 & -1.41 & 0.16 \\
\hline 2. Arithmetic operation based & $\begin{array}{c}11.4 \\
(10.85)\end{array}$ & $\begin{array}{l}9.16 \\
(8.3)\end{array}$ & 9 & 8 & -1.61 & 0.11 \\
\hline 3. Picture based & $\begin{array}{c}26.78 \\
(29.53)\end{array}$ & $\begin{array}{c}24.34 \\
(23.55)\end{array}$ & 18 & 18.5 & -0.63 & 0.53 \\
\hline 4. Game based & $\begin{array}{c}21.07 \\
(13.05) \\
\end{array}$ & $\begin{array}{c}20.34 \\
(16.33) \\
\end{array}$ & 17 & 17 & -0.31 & 0.76 \\
\hline 5. "NO CAPTCHA" based & $\begin{array}{c}19.32 \\
(22.74) \\
\end{array}$ & $\begin{array}{l}18.97 \\
(23.6)\end{array}$ & 11.5 & 13 & -0.10 & 0.92 \\
\hline
\end{tabular}


The success rate was calculated for each test. Table 8 presents the results and the statistical comparison, using the Pearson Chi-square test $(\mathrm{p}<0.05)$, indicating that there is a significant dependence between the test success and the existence of LD only for text -based CAPTCHA, bringing the LD users to fail more often. The arithmetic test is more difficult for all populations.

Table 8. Comparison of the CAPTCHA types - Success Rates

\begin{tabular}{|c|c|c|c|c|c|c|}
\hline CAPTCHA type & $\begin{array}{c}\text { Success } \\
\text { Rate }\end{array}$ & $\begin{array}{c}\text { LD } \\
\text { users } \\
(n=60)\end{array}$ & $\begin{array}{c}\text { Non-LD } \\
\text { users } \\
(n=152)\end{array}$ & $\begin{array}{c}\chi^{2} \\
\text { value }\end{array}$ & df & $\begin{array}{c}\text { Sig. } \\
(2- \\
\text { tailed) }\end{array}$ \\
\hline \multirow{3}{*}{ 1. Text based } & $\%$ & $58.33 \%$ & $74.34 \%$ & & & \\
\hline & Pass & 35 & 113 & \multirow{2}{*}{5.23} & \multirow{2}{*}{1} & \multirow{2}{*}{0.022} \\
\hline & Fail & 25 & 39 & & & \\
\hline \multirow{3}{*}{ 2. Arithmetic operation based } & $\%$ & $48.33 \%$ & $50 \%$ & & & \\
\hline & Pass & 29 & 76 & \multirow{2}{*}{0.048} & \multirow{2}{*}{1} & \multirow{2}{*}{0.83} \\
\hline & Fail & 31 & 76 & & & \\
\hline \multirow{3}{*}{ 3. Picture based } & $\%$ & $68.33 \%$ & $73.03 \%$ & & & \\
\hline & Pass & 41 & 111 & \multirow{2}{*}{0.47} & \multirow{2}{*}{1} & \multirow{2}{*}{0.49} \\
\hline & Fail & 19 & 41 & & & \\
\hline \multirow{3}{*}{ 4. Game based } & $\%$ & $83.33 \%$ & $82.89 \%$ & & & \\
\hline & Pass & 50 & 126 & \multirow{2}{*}{0.01} & \multirow{2}{*}{1} & \multirow{2}{*}{0.96} \\
\hline & Fail & 10 & 26 & & & \\
\hline \multirow{3}{*}{ 5. "NO CAPTCHA" based } & $\%$ & $86.67 \%$ & $89.47 \%$ & & & \\
\hline & Pass & 52 & 136 & \multirow{2}{*}{0.34} & \multirow{2}{*}{1} & \multirow{2}{*}{0.56} \\
\hline & Fail & 8 & 16 & & & \\
\hline
\end{tabular}

\section{Discussion}

Findings suggest that users with learning disabilities have more difficulties in solving the tests, especially those with distorted texts, and have more negative attitudes towards the CAPTCHA tests than other users. Surprisingly, there was no significant difference found in response times, between users with learning disabilities and those without in any of the five test types, thus, rejecting H1, which claimed that "The performance time of users with learning disabilities will be longer in text and arithmetic based tests". The reason H1 was not supported may be the fact that CAPTCHA tests have become so common that the users are getting used to the twisted letters. Another reason for this finding may be due to a certain level of impulsiveness in users with learning disabilities. According to estimates done on children with dyslexia, $30 \%$ have at least a mild form of ADHD, which is characterized by hyperactivity, inattentive and impulsive behavior (Lee, 2015).

However, a significant difference was found in the test success rates between the two kinds of users for only the text-based CAPTCHA. In all other types of CAPTCHA there were no differences between the groups. Thus, H2.1, claiming that 'The success rate of users without learning 
disabilities will be greater' was partially rejected, supporting the position of Hsu \& Lee (2011), who claim that even the non-impaired population might encounter difficulties with CAPTCHA tests. Their study was one of the first to examine CAPTCHA tests from the users' perspective. These findings, in fact, confirm the widespread notion that CAPTCHA tests are difficult for people.

In addition, H2.2 which claims that 'Users with learning disabilities will succeed better in tests, which do not include letters' was accepted, meaning that users with learning disabilities have more difficulties in reading the distorted texts, supporting Foley's study (2012), but they have no problems performing other tasks. Perhaps, if those users had spent more time to resolve the test, the success rate would have been better, in spite of their learning disabilities.

A significant difference in the user-experience attitude was found for 'Frustrating' and 'Unwillingness to use the Website' between users with learning disabilities and the those without, where users with learning disabilities had a more negative attitude towards the tests, accepting H3.1, which claims that 'Attitude and user experience of users with learning disabilities will be more negative'. The most negative attitude of the users with learning disabilities was found in the textbased and arithmetic-based CAPTCHA, supporting H3.2, which claims that 'Users with learning disabilities will report better experience in tests, which do not include letters'.

\section{Conclusions}

The main conclusion of this research is that all five types of tests influenced user experience to a certain degree, from frustration to enjoyment. Users with learning disabilities found it more difficult to succeed in the text-based CAPTCHA, and there was a significant difference found between participants with learning disabilities and those without learning disabilities in most users' experiences constructs examined.

According to the International Dyslexia Association (International Dyslexia Association, n.d.), overcoming dyslexia and other learning difficulties can be achieved through multisensory reeducation, which involves the use of visual, auditory, and kinesthetic-tactile pathways simultaneously in order to enhance memory and written language learning. The Web is a very useful tool for individuals with disabilities. Therefore, it is important for organizations to design Web sites that are accessible by all kinds of individuals. The Internet helps improve the life of individuals with disabilities, and Web accessibility can improve the experience of these populations. In order to create accessible Web sites, Web developers need to follow the guidelines set by the W3C (2008). It is easier to develop an accessible site from scratch, than to improve an existing one (White et al., 2005). Accordingly, designing CAPTCHA tests adapted for users with learning disabilities is necessary.

It appears that appropriate and careful reference to the findings and conclusions of this research on the part of user experience experts, developers, and web designers can lead in the future to applying solutions that are more suitable for many users and especially for populations with learning disabilities. Such solutions could benefit significantly the accessibility of the Internet and improve the user experience on many Websites.

As described, the game-based CAPTCHA tests may be the best choice for users with learning disabilities. Still, it should be noted that visually impaired users might take more time to solve a test of this type.

The solution chosen by the developers of the Website must take into consideration, on the one hand, the security level needed and, on the other hand, the user experience and frustration in solving the test. 


\section{Limitations and Further Research}

The main limitations of this study are the following:

(1) The small number of participants with learning disabilities compared with those without (60 with LD, and 152 without). A larger number of users with learning disabilities might have provided a better representative sample.

(2) The definition of users with learning disabilities - some were diagnosed, some were selfreported, but not diagnosed, and others may be not aware of having learning disabilities.

Further research is needed, especially for the "No CAPTCHA" test, where findings were unclear. This test seems obvious and easy to perform, for all the population, regardless of any disability. For instance, it would be good to examine separately how many users were presented with an additional task to complete after this test, and in which cases it is being used.

Another recommendation for future research would be to examine the influence of different devices in solving CAPTCHA tests, e.g., through mobile phones or computers, on performance and especially on user experience. It may be found, that performing those tests on touch-screens, like in smartphones and tablets, are easier than on a desk-computer, in which a keyboard and a mouse must be used. However, if typing is needed, a larger screen and keyboard may be more comfortable for users with learning disabilities. A study about CAPTCHA tests has been recently conducted, using Nielsen's heuristic evaluation (Reynaga, Chiasson, \& van Oorschot, 2015). Their research's aim was to propose and validate a set of heuristics for evaluating CAPTCHA schemes on smartphones. However, they did not investigate the issue among specific sensitive populations, in the way suggested here.

\section{References}

Abrich, R., Berbenetz, V., \& Thorpe, M. (2011). Distinguishing between humans and robots on the Web. Retrieved December 1, 2014, from http://richardabrich.com/abrich-berbenetzthorpe thecaptchaexperiment.pdf

Ahn, Y., Kim, N., \& Kim, Y. S. (2013). A user- friendly image-text fusion CAPTCHA for secure web services. In Proceedings of International Conference on Information Integration and Web-based Applications \& Services, 550-554.

Angre, A. R., Kapadia, M. D., \& Ugale, M. (2015). PiCAPTion: Picture CAPTCHAs for internet authentication. International Journal of Computer Applications, 114(10).

Azad, K. J. (2013). CAPTCHA: Attacks and weaknesses against OCR technology. Global Journal of Computer Science and Technology, 13(3).

Baltar, F., \& Brunet, I. (2012). Social research 2.0: Virtual snowball sampling method using Facebook. Internet Research, 22(1), 57-74.

Bevan, N. (2009). What is the difference between the purpose of usability and user experience evaluation methods. UXEM'09 Workshop, Upssala, Sweden.

Bursztein, E., Bethard, S., Fabry, C., Mitchell, J. C., \& Jurafsky, D. (2010). How good are humans at solving CAPTCHAs? A large scale evaluation. In Security and Privacy (SP), Symposium on Security and Privacy IEEE, 399-413.

Fidas, C., Voyiatzis, A., \& Avouris, N. (2011). On the necessity of user-friendly CAPTCHA. In Proceedings of the SIGCHI Conference on Human Factors in Computing Systems, 2623-2626.

Foley, A. (2012). Biometric alternatives to CAPTCHA: Exploring accessible interface options. Masters Dissertation, Dublin Institute of Technology, Ireland.

Ghazarian, A. (2014). CAPTCHAs' effect on UX and how to fix it. Retrieved December 15, 2014, from DesignModo: http://designmodo.com/ux-captcha-effect 
Gossweiler, R., Kamvar, M., \& Baluja, S. (2009). What's up CAPTCHA? A CAPTCHA based on image orientation. In Proceedings of the 18th international conference on $W W W, 841-850$.

Hammill, D. D. (1990). On defining learning disabilities: An emerging consensus. Journal of learning Disabilities, 23(2), 74-84.

Hande, S. G., \& Ali, M. S. (2015). Enhancing the security using CAPTCHA as a graphical password. International Journal of Advance Research in Computer Science and Management Studies, 3(4), 346352.

Hsu, C.-H., \& Lee, Y. -L. (2011). Effects of age groups and distortion types on text-based CAPTCHA tasks. In J. A. Jacko (Ed.), Human-computer interaction. Users and Applications (pp. 435-455). New York: Springer-Verlag Berlin Heidelberg publications.

International Dyslexia Association. (n.d.). Multisensory structured language teaching. Retrieved June 7, 2016, from: http://eida.org/multisensory-structured-language-teaching/

Katchergin, O. (2015). How many learning disabled are there? The rhetorical power of statistics in the Israeli discourse on learning disabilities. Open Journal of Social Sciences, 3(09), 155-166.

Lee, R. (2015). Dyslexia font simulates how it's like to read if you're dyslexic. TechTimes. Retrieved June 9, 2016, from http://www.techtimes.com/articles/58567/20150608/dyslexia-font-simulates-how-itslike-to-read-if-youre-dyslexic.htm

Madeira, J., Silva, C., Marcelino, L., \& Ferreira, P. (2015). Assistive mobile applications for dyslexia. Procedia Computer Science, 64, 417-424.

Matej, S. (2013). Strict standards: Introduction to CAPTCHA accessibility. Retrieved June 1, 2014, from CAPTCHA.com: http://captcha.com/captcha-accessibility.html

McCarthy, J. E., \& Swierenga, S. J. (2010). What we know about dyslexia and web accessibility: A research review. Universal Access in the Information Society, 9, 147-152.

Mohamed, M., Sachdeva, N., Georgescu, M., Gao, S., Saxena, N., Zhang, C., \& Chen, W. B. (2013). Three-way dissection of a game-CAPTCHA: Automated attacks, relay attacks, and usability. Cornell University. New York: arXiv:1310.1540.

Mujumdar, D., \& Polisetti, S. (2011). A platform to monetize usable \& secure CAPTCHAs for desktop and mobile devices (PICATCHA). Retrieved Dec 20, 2014, from Kevinwarnock:

http://www.kevinwarnock.com/wpcontent/uploads/2012/05/picatcha_mims_final_report_summary_0.pdf

National Joint Committee on Learning Disabilities (NJCLD). (1994). Learning disabilities: Issues on definition-revised. In NJCLD (Ed.), Collective perspectives on issues affecting learning disabilities (pp. 61-66). Austin, TX: Pro-Ed.

Onwudebelu, U., Sanjo, F., Obi, N. C., \& Alaba, O. B. (2010). CAPTCHA malaise: Users suffer consequences of the anti-spam technology while the spammers adapt. In Proceeding of the 1st International Conference and Workshop on Software Engineering and Intelligent Systems, 113-125.

Pascual, A., Ribera, M., \& Granollers, T. (2015). Impact of web accessibility barriers on users with a hearing impairment. Dyna, 82(193), 233-240.

ReCAPTCHA. (n.d.). In Wikipedia. Retrieved May 8, 2016, from https://en.wikipedia.org/wiki/ReCAPTCHA

Reddy, K. V., Krishna, D. S. R., \& Reddy, D. J. (2015). CAPTCHA and its techniques for providing security in web and applications. International Journal of Research, 2(8), 815-821.

Reynaga, G., Chiasson, S., \& van Oorschot, P. C. (2015). Heuristics for the evaluation of CAPTCHAs on smartphones. In Proceedings of the 2015 British HCI Conference, ACM 126-135.

Robson, K., Plangger, K., Kietzmann, J. H., McCarthy, I., \& Pitt, L. (2015). Is it all a game? Understanding the principles of gamification. Business Horizons, 58(4), 411-420 
Sagirani, T., Nugroho, L. E., Santosa, P. I., \& Kumara, A. (2015). User experience model in the interaction between children with special educational needs and learning media. In 2015 2nd International Conference on Information Technology, Computer, and Electrical Engineering (ICITACEE) (pp. 72-75). IEEE.

Saini, B. S., \& Bala, A. (2013). A review of bot protection using CAPTCHA for web security, IOSR Journal of Computer Engineering, 6, 36-42.

Shirali-Shahreza, M. H., \& Shirali-Shahreza, M. (2006). Persian/Arabic CAPTCHA. In Proceedings of the IADIS International Conference on Applied Computing (pp. 258-265).

Singh, P. V., \& Pal, P. (2014). Survey of different types of CAPTCHA. International Journal of Computer Science and Information Technologies, 5(2), 2242-2245.

Tangmanee, C., \& Sujarit-apirak, P. (2013). Attitudes towards CAPTCHA: A survey of Thai internet users. The Journal of Global Business Management, 9, 29-41.

Von Ahn, L., Blum, M., \& Langford, J. (2004). Telling humans and computers apart automatically. Communications of the ACM, 47(2), 56-60.

W3C. (2008). Web Content Accessibility Guidelines (WCAG) 2.0. Retrieved December 10, 2014, from World Wide Web Consortium: http://www.w3.org/TR/WCAG20

White, J., Goette, T., \& D. Young, D. (2005). Measuring the accessibility of the U.S. State Government web sites. Communications of the International Information Management Association 5(1), 31-40.

WHO. (2015). Fact sheet $N^{\circ} 300$ : Deafness and hearing loss. World Health Organization. Retrieved June 7, 2016, from: http://www.who.int/mediacentre/factsheets/fs300/en/

Williams, P., \& Hennig, C. (2015). Effect of web page menu orientation on retrieving information by people with learning disabilities. Journal of the Association for Information Science and Technology, 66(4), 674-683.

\section{Biographies}

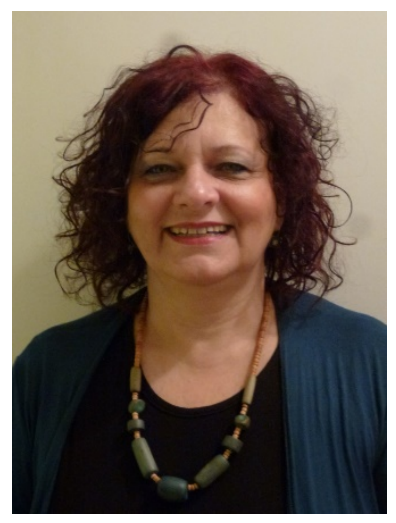

Ruti Gafni is the Head of the Information Systems B.Sc. program at The Academic College of Tel Aviv Yaffo. She holds a PhD from BarIlan University, Israel (in the Business Administration School), focusing on Information Systems, an M.Sc. from Tel Aviv University and a BA (Cum Laude) in Economics and Computer Science from Bar-Ilan University. She has more than 30 years of practical experience as Project Manager and Analyst of information systems. She also teaches in the Management and Economics MBA program at the Open University of Israel.

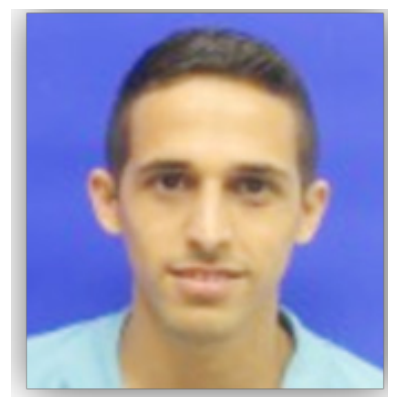

Idan Nagar is a graduate of the Information Systems B.Sc. program at The Academic College of Tel Aviv Yaffo, and a student of the MA Interdisciplinary design innovation and entrepreneurship at The College of Management Academic Studies. He worked as an Information Systems implementer, and served as a data analyst in the Israeli Air Force. Idan is a Mobile-Web developer, especially interested in $\mathrm{Hu}-$ man-Computer Interaction and particularly in UI/UX design, development and measurement 